SISOMOS

AMERICANOS

Revista de Estudios

Transfronterizos
Volumen XXI, número l,

enero-junio de 2021

Recibido: 21 de abril de 2020

Aprobado: 25 de enero de 2021

\title{
Integración, turismo y Mercosur: reflexiones sobre los visitantes regionales en la ciudad de Buenos Aires*
}

\section{Integration, tourism and Mercosur: reflections about regional visitants in Buenos Aires}

\author{
Bárbara Catalano* $^{* *}$ \\ Instituto de Investigaciones Gino Germani, Buenos Aires, Argentina.
}

\begin{abstract}
Resumen
Partiendo del presupuesto que la integración regional es posible de ser estudiada a través de enfoques multidisciplinarios, este trabajo aborda la integración social desde los estudios del turismo. El objetivo de este artículo es comprender las vinculaciones entre el Mercosur, como proceso de integración, y los turistas regionales que visitan la ciudad de Buenos Aires. La metodología es cualitativa basada en entrevistas en profundidad a turistas e informantes clave, por medio de las cuales se indaga sobre las representaciones de extranjeridad, familiaridad y hermandad entre turistas y residentes. Se analiza también el significado que representa el Mercosur para los turistas, los determinantes de extranjeridad por parte de los sujetos y los indicadores de hermandad o unidad entre los visitantes y el destino y sociedad receptora. Como resultados se
\end{abstract}

\footnotetext{
* Este trabajo es parte de la tesis de doctorado en ciencias sociales titulada "Turismo y Mercosur: prácticas socioculturales de integración en la ciudad de Buenos Aires", defendida en diciembre de 2018, financiada por el Consejo Nacional de Investigaciones Científicas y Técnicas (CONICET). El trabajo de campo se ha realizado bajo consentimiento informado de los entrevistados, quienes aceptaron y accedieron a la entrevista, y cuya información, extraída de los relatos, sea analizada e interpretada por la investigadora.

** Doctora en Ciencias Sociales, Universidad de Buenos Aires. Magíster en Procesos de Integración Regional, Universidad de Buenos Aires. Licenciada en Turismo, Universidad del Salvador, Argentina. Becaria posdoctoral del CONICET, con asiento en el Instituto de Investigaciones Gino Germani. Dirección postal: Uriburu 950, piso 6, Buenos Aires, Argentina. Correo electrónico: Catalano81@gmail.com ORCID: https://orcid.org/0000-0002-7565-845.
}

Cómo citar este artículo: Catalano, B. (2021) Integración, turismo y Mercosur: reflexiones sobre los visitantes regionales en la ciudad de Buenos Aires. Si Somos Americanos. Revista de Estudios Transfronterizos, 21(1), 78102. doi: $10.4067 / \mathrm{S} 0719-09482021000100078$ 
destaca una desarticulación entre las categorías analíticas y empíricas en torno a la integración regional y el Mercosur, y una preeminencia del eje de las movilidades. El tiempo incurrido en el viaje, la receptividad, la comunicación y la historia común emergen como determinantes de extranjeridad/hermandad entre los visitantes y la población receptora.

Palabras clave: integración, turismo, Mercosur.

\begin{abstract}
Starting from the assumption that regional integration is studied from multidisciplinary approaches, this paper addresses social integration from tourism. The objective of this work is to understand the links between Mercosur, as an integration process, and the regional tourists who visit the city of Buenos Aires. The methodology is qualitative based on in-depth interviews with tourists and key informants, where the representations of foreignness, familiarity and brotherhood among tourist and residents are investigated. The meaning that Mercosur represents for tourists, the determinants of foreignness on the part of the subjects and the indicators of brotherhood or unity between the visitors and the destination and receiving society are analyzed. The results highlight a gap between the analytical and empirical categories around regional integration and Mercosur and a preeminence of the axis of mobility. The time incurred in the trip, the receptivity, the communication and the common history emerge as determinants of foreignness / brotherhood between the visitors and the receiving population.
\end{abstract}

Keywords: integration, tourism, Mercosur.

\title{
Introducción
}

Los procesos de integración regional, en general, y el caso del Mercosur, en particular, son analizados desde diversos enfoques como las relaciones internacionales, las políticas públicas, la historia, o bien, desde abordajes económico-comerciales, tales como los estudios sectoriales que abordan la integración productiva y el comercio intrarregional (Briceño Ruiz, 2011). El Mercosur implica un proceso de integración económico, pero también social y cultural, sobre todo teniendo en cuenta las sociedades que son parte en dichos procesos, la identidad común y la historia compartida (Grimson, 2001).

También se aborda el Mercosur desde las movilidades, en términos de políticas migratorias regionales y derechos sobre la circulación y permanencia de los sujetos ciudadanos implicados en este tratado (Modolo, 2012; Novick, 2013). A su vez, desde este enfoque se observan trabajos que abordan la circulación de factores productivos, 
movilidad de personas con fines laborales, o profesionales, entre otros (Botto, 2015; Solanas, 2014).

Al referirnos a las movilidades, también se hace referencia a los viajes turísticos de los ciudadanos del Mercosur, como un tipo de movilidad temporal que representa un impacto en lo económico, social y cultural de los países receptores (Bertoncello, 2002; Catalano et al., 2017; Vellas, 2004). Los viajes turísticos, en general, y los transfronterizos, en particular, pueden considerarse vectores de integración, ya que dichas prácticas contribuyen a la estructuración de una dinámica transfronteriza, es decir, a la aproximación entre los actores locales, privados y públicos (Amilhat Szary, 2009).

Dentro de la órbita de las movilidades turísticas, en este trabajo se aborda el caso de los turistas del Mercosur que visitan la ciudad de Buenos Aires, en particular en términos de integración social por parte de los sujetos móviles en relación con su destino, concibiendo a los turistas como sujetos móviles, portadores de cultura, que circulan e interactúan con otras sociedades en espacios en los que se despliegan las prácticas y relaciones sociales (Crang, 1998).

Para ello, se parte de ciertos discursos legitimadores sobre el turismo que lo asocian con la unión e integración entre los pueblos. Esta idea sobre el turismo como vector de unión radica en la construcción de significados y legitimidad sobre concebir al turismo como un inductor al intercambio de ideas. Esos argumentos se desprenden de organismos tales como la Organización Mundial del Turismo (OMT) o la Organización de las Naciones Unidas para la Educación, la Ciencia y la Cultura (UNESCO), entidades que conciben el turismo como herramienta de paz, ya que los flujos turísticos constituirían la posibilidad de construir y consolidar nuevas relaciones entre las personas, como también una solidaridad socioeconómica, un encuentro entre los pueblos y un instrumento de diálogo entre las civilizaciones. ${ }^{1}$ En esa línea, el objetivo primero de este artículo es comprender las vinculaciones entre el Mercosur, como proceso de integración, y los turistas regionales que visitan la ciudad de Buenos Aires. Con esa finalidad es que se realiza un estudio de caso que atestigüe en qué medida los turistas perciben integración o unión a través de sus viajes hacia un destino del Mercosur, concebido este como un bloque de integración regional.

A pesar de que estudiar el Mercosur desde las ciencias sociales implica un desafío y un proceso lleno de escollos (De Sierra, 2001), se ha decidido trabajar la integración desde un aspecto microsocial, entendiendo que los instrumentos propios de la escala interestatal no alcanzan la comprensión profunda de las relaciones sociales entre los turistas y el lugar y sociedad visitados.

\footnotetext{
${ }^{1}$ Ello se observa, por ejemplo, en la Declaración de Siem Reap sobre turismo y cultura: construyendo un nuevo modelo de cooperación (UNWTO y UNESCO, 2015), en la que se especifica que el turismo integra la cultura, reduce obstáculos y facilita las asociaciones en el ámbito regional y local.
} 
Por lo anterior, a modo de transpolar el nivel de integración global que implica el Mercosur hacia un nivel microsocial por parte de los sujetos que realizan viajes turísticos, es que se analiza en primer lugar el significado que representa el Mercosur para los turistas, desarrollando las distintas connotaciones que emergen de los relatos de los entrevistados. En segundo lugar, se examinan las concepciones de extranjeridad percibidas por los turistas en sus estadías, ya que se concibe la extranjeridad como el opuesto a la integración entre los sujetos nacionales distintos. ${ }^{2}$ Finalmente, se analizan aspectos de identidad colectiva y las variables que emergen como determinantes de unidad entre los sujetos dentro de un territorio común.

\section{Modo de abordaje y metodología}

Se comprende la metodología cualitativa como procedimientos para la construcción de la evidencia empírica (Sautu, Boniolo, Dalle y Elbert, 2005), ya que facilita el diálogo entre los supuestos teóricos y paradigmas sobre ciertos aspectos de la realidad. La elección de este tipo de metodología se condice con el objetivo principal de la investigación, que busca una mayor comprensión sobre la relación entre la integración desde un plano regional y la integración social a partir de las prácticas y representaciones de los sujetos sociales móviles en su condición de turistas.

Se realizaron 30 entrevistas en profundidad a turistas provenientes de Brasil, Paraguay, Uruguay y Chile en los establecimientos donde se alojaban, ya fuesen hoteles o hostels y a 12 informantes clave, en particular, guías e informantes de turismo, durante el año 2016 (Ver Cuadro 1 y 2). Se utiliza esa técnica de recolección ya que permite comprender los valores culturales del comportamiento social, como también captar los matices de la vida humana. A su vez, se emplea el microanálisis, incluyendo la codificación axial y abierta que permiten hacer uso de las múltiples técnicas analíticas, como también examinar e interpretar datos de manera cuidadosa, y a menudo hasta minuciosa.

Por otra parte, se acude a la reflexividad como forma de interpretación de los relatos de los entrevistados, concibiendo esta como la íntima relación entre la comprensión y la expresión de dicha comprensión. El relato es el soporte y vehículo de esta intimidad, por ello la reflexividad supone que las actividades realizadas para producir y manejar las situaciones de la vida cotidiana son idénticas a los procedimientos empleados para describir esas situaciones (Coulon cit. en Guber, 2001). Se implementa la articulación de la reflexividad con la teoría social y la práctica social, concebida esta como la acción de los individuos que tiene un principio ordenador, condicionante de la existencia de esas acciones.

2 Los sustentos teóricos de dicha afirmación se exponen en los apartados siguientes. 
Con el fin de lograr una operacionalización fiable que permita transpolar las nociones conceptuales sobre el Mercosur y la integración desde un nivel microsocial, se plantean las preguntas que facilitan un acercamiento hacia el objetivo principal de la investigación. Algunas de ellas son las siguientes: ¿saben qué es el Mercosur?, ¿qué piensan qué es?; ¿qué piensan sobre la integración regional?; ¿se sintieron extranjeros en el destino?; ¿piensan que tienen cosas en común con los residentes del lugar? La elaboración del cuestionario fue producto de un proceso en el que se trabaja con la dialéctica entre los espectros conceptuales de la integración y su pasaje hacia dimensiones microsociales.

El muestreo es no probabilístico y la selección de los turistas entrevistados se realiza por intermedio de los responsables de los establecimientos hoteleros. Las entrevistas se realizaron en el momento del desayuno, y el espacio fue consensuado y facilitado por los gerentes de cada establecimiento, así como la cantidad de las mismas fue determinado bajo el criterio de saturación.

Cabe destacar que el presente trabajo es parte de una investigación mayor en la que se analizó el turismo y su articulación con los procesos de integración en diversos niveles, por lo que en este artículo se expone un recorte de un tema mayor, profundizando en las relaciones entre el Mercosur y la percepción sobre la integración por parte de los turistas.

Cuadro $\mathrm{N}^{\circ}$ 1: Grilla de relevamiento de entrevistas a informantes

\begin{tabular}{|c|c|c|c|c|}
\hline & \multirow[b]{2}{*}{ Rol en turismo } & \multirow[b]{2}{*}{$\begin{array}{l}\text { Fecha de } \\
\text { entrevista }\end{array}$} & \multicolumn{2}{|c|}{$\begin{array}{l}\text { Modalidades y aspectos del turismo sobre el } \\
\text { que presenta conocimiento y experiencia }\end{array}$} \\
\hline & & & $\begin{array}{c}\text { Experiencia en } \\
\text { determinados } \\
\text { servicios turísticos o } \\
\text { tipo de contacto con } \\
\text { turista }\end{array}$ & $\begin{array}{l}\text { Perfiles de turistas } \\
\text { sobre el que } \\
\text { presenta } \\
\text { acumulación de } \\
\text { conocimientos }\end{array}$ \\
\hline 1 & Guía & $16 / 4 / 2016$ & $\mathrm{WT} / \mathrm{TRF} / \mathrm{BT} / \mathrm{FT}$ & $\begin{array}{l}\text { Turistas de Mercosur } \\
\text { alojados que se } \\
\text { alojan en hostels, } \\
\text { hoteles, VFA. }\end{array}$ \\
\hline 2 & $\begin{array}{c}\text { Guía de turismo } \\
\text { CABA }\end{array}$ & $2 / 9 / 2016$ & Tem / CT & $\begin{array}{l}\text { Turistas Mercosur } \\
\text { alojados que se } \\
\text { alojan en hostels, } \\
\text { hoteles, VFA. }\end{array}$ \\
\hline 3 & Guía & $5 / 5 / 2016$ & Servicios en privado & $\begin{array}{l}\text { Turistas Mercosur } \\
\text { alojados que se } \\
\text { alojan en hoteles }\end{array}$ \\
\hline 4 & Guía & $6 / 6 / 2016$ & Servicios en privado & $\begin{array}{c}\text { Turistas Mercosur } \\
\text { hotel } 4 * \text { y } 5 * / \\
\text { turistas de reuniones }\end{array}$ \\
\hline 5 & Guía & $2 / 3 / 2016$ & $\begin{array}{c}\text { Servicios regulares y } \\
\text { privados }\end{array}$ & $\begin{array}{l}\text { Turistas Mercosur } \\
\text { alojados que se } \\
\text { alojan en hoteles }\end{array}$ \\
\hline
\end{tabular}




\begin{tabular}{|c|c|c|c|c|}
\hline 6 & Guía & $2 / 3 / 2016$ & $\begin{array}{c}\text { Servicios regulares y } \\
\text { privados }\end{array}$ & $\begin{array}{l}\text { Turistas Mercosur } \\
\text { alojados que se } \\
\text { alojan en hoteles }\end{array}$ \\
\hline 7 & Guía BR & $17 / 6 / 2016$ & $\begin{array}{c}\text { Servicios regulares y } \\
\text { privados }\end{array}$ & $\begin{array}{c}\text { Turistas brasileros } \\
\text { HTL }\end{array}$ \\
\hline 8 & Guía BR & $19 / 10 / 2016$ & $\begin{array}{c}\text { Venta de excursiones a } \\
\text { brasileros }\end{array}$ & $\begin{array}{c}\text { Turistas brasileros } \\
\text { HTL }\end{array}$ \\
\hline 9 & Guía WT & $23 / 3 / 2016$ & WT & $\begin{array}{c}\text { Turistas Mercosur } \\
\text { múltiples } \\
\text { alojamientos } \\
\end{array}$ \\
\hline 10 & Guías WT & $18 / 7 / 2016$ & WT & $\begin{array}{c}\text { Turistas Mercosur } \\
\text { múltiples } \\
\text { alojamientos } \\
\end{array}$ \\
\hline 11 & Guía WT & $8 / 12 / 2016$ & WT & $\begin{array}{c}\text { Turistas Mercosur } \\
\text { múltiples } \\
\text { alojamientos } \\
\end{array}$ \\
\hline 12 & Informante & $15 / 9 / 2016$ & $\begin{array}{c}\text { Informar / asistir a } \\
\text { turistas }\end{array}$ & $\begin{array}{c}\text { Turistas Mercosur } \\
\text { múltiples } \\
\text { alojamientos } \\
\end{array}$ \\
\hline 13 & $\begin{array}{l}\text { Información al } \\
\text { turista }\end{array}$ & 9/9/2016 & $\begin{array}{c}\text { Informar / asistir a } \\
\text { turistas }\end{array}$ & $\begin{array}{c}\text { Turistas Mercosur } \\
\text { múltiples } \\
\text { alojamientos } \\
\end{array}$ \\
\hline 14 & Informante/guía & $24 / 9 / 2016$ & $\begin{array}{c}\text { Informar / asistir a } \\
\text { turistas }\end{array}$ & $\begin{array}{c}\text { Turistas Mercosur } \\
\text { múltiples } \\
\text { alojamientos }\end{array}$ \\
\hline 15 & Informante/guía & $15 / 9 / 2016$ & $\begin{array}{c}\text { Informar / asistir a } \\
\text { turistas }\end{array}$ & $\begin{array}{c}\text { Turistas Mercosur } \\
\text { múltiples } \\
\text { alojamientos }\end{array}$ \\
\hline 16 & Nexo & $9 / 3 / 2016$ & $\begin{array}{l}\text { nexo de turistas } \\
\text { brasileros VFA }\end{array}$ & $\begin{array}{c}\text { Turistas brasileros } \\
\text { VFA }\end{array}$ \\
\hline 17 & Nexo & $1 / 9 / 2016$ & $\begin{array}{l}\text { nexo de turistas } \\
\text { brasileros VFA } \\
\end{array}$ & $\begin{array}{c}\text { Turistas brasileros } \\
\text { VFA }\end{array}$ \\
\hline 18 & Recepcionista hstl & $7 / 10 / 2016$ & $\begin{array}{l}\text { Informar / asistir / } \\
\text { vender excursiones }\end{array}$ & $\begin{array}{c}\text { Turistas Mercosur } \\
\text { hostel }\end{array}$ \\
\hline 19 & Recepcionista hstl & $21 / 10 / 2016$ & $\begin{array}{l}\text { Informar / asistir / } \\
\text { vender excursiones }\end{array}$ & $\begin{array}{c}\text { Turistas Mercosur } \\
\text { hostel }\end{array}$ \\
\hline 20 & Recepcionista hstl & $10 / 10 / 2016$ & $\begin{array}{l}\text { Informar / asistir / } \\
\text { vender excursiones }\end{array}$ & $\begin{array}{c}\text { Turistas Mercosur } \\
\text { hostel }\end{array}$ \\
\hline 21 & $\begin{array}{c}\text { Referente turismo } \\
\text { BR }\end{array}$ & $15 / 10 / 2016$ & $\begin{array}{l}\text { vender excursiones / } \\
\text { asesorías sobre } \\
\text { trámites de residencia / } \\
\text { turismo estudiantil }\end{array}$ & $\begin{array}{c}\text { Turistas Mercosur } \\
\text { múltiples } \\
\text { alojamientos / } \\
\text { Turistas brasileros } \\
\text { estudiantes } \\
\end{array}$ \\
\hline 22 & Gerente HTL 4* & 29/10/2016 & $\begin{array}{l}\text { industria turística de } \\
\text { nivel } 4 \text { y } 5 * / \\
\text { evolución histórica / } \\
\text { requerimientos turistas }\end{array}$ & $\begin{array}{l}\text { Turistas Mercosur } \\
\text { hotel } 4 * \text { y } 5 * / \\
\text { turistas de reuniones }\end{array}$ \\
\hline
\end{tabular}




\begin{tabular}{|c|c|c|c|c|}
\hline 23 & $\begin{array}{l}\text { Gerente HTL 3* } \\
\text { superior }\end{array}$ & $12 / 11 / 2016$ & $\begin{array}{c}\text { industria turística de } \\
\text { nivel hostel, } 3^{*}, 4^{*} \text { y } \\
5^{*} / \text { evolución } \\
\text { histórica / } \\
\text { requerimientos turistas }\end{array}$ & $\begin{array}{l}\text { Turistas Mercosur / } \\
\text { hostels, hotel } 4 * \text { y } 5^{*} \\
\text { / turistas de } \\
\text { reuniones }\end{array}$ \\
\hline 24 & $\begin{array}{l}\text { Encuestador } \\
\text { CABA }\end{array}$ & 26/9/2016 & $\begin{array}{c}\text { abordaje a turistas para } \\
\text { encuestar / perfiles }\end{array}$ & $\begin{array}{l}\text { Turistas reuniones o } \\
\text { en sitios turísticos }\end{array}$ \\
\hline
\end{tabular}

Fuente: elaboración propia basada en la sistematización del trabajo de campo.

(Ver Tabla 1 para aclarar abreviaturas)

Tabla 1. Abreviaturas

\begin{tabular}{cc}
\hline WT & Excursiones caminando \\
\hline TRF & Traslados \\
\hline BT & Excursiones en bicicleta \\
\hline FT & Excursiones de futbol \\
\hline Tem & Excursiones temáticas \\
\hline CT & City tour / excursión clásica por la ciudad \\
\hline VFA & Vienen a visitar amigos y/o familiares \\
\hline HSTL & Hostal \\
\hline HTL & Hotel \\
\hline
\end{tabular}

Cuadro $N^{\circ}$ 2: Grilla de relevamiento de entrevistas a turistas

\begin{tabular}{|c|c|c|c|c|c|c|c|}
\hline & País & $\begin{array}{c}\text { Lugar de } \\
\text { residencia } \\
\text { habitual }\end{array}$ & $\begin{array}{c}\text { alojamie } \\
\text { nto } \\
\text { utilizado }\end{array}$ & $\begin{array}{c}\text { Último } \\
\text { tipo de } \\
\text { modali } \\
\text { dad } \\
\end{array}$ & $\begin{array}{c}\text { Modalidades } \\
\text { anteriores }\end{array}$ & $\begin{array}{l}\text { Fecha de } \\
\text { entrevista }\end{array}$ & $\begin{array}{c}\text { Veces } \\
\text { que } \\
\text { visitó } \\
\text { Bs As } \\
\end{array}$ \\
\hline 1 & Brasil & Petrópolis & DEP & EST & - & $12 / 8 / 2016$ & 1 \\
\hline 2 & Brasil & Joinville & $\begin{array}{c}\mathrm{DEP} / \mathrm{HS} \\
\mathrm{TL}\end{array}$ & EST & - & $15 / 8 / 2016$ & 1 \\
\hline 3 & Brasil & $\begin{array}{c}\text { Santa } \\
\text { Catarina }\end{array}$ & $\begin{array}{c}\mathrm{DEP} / \mathrm{HS} \\
\mathrm{TL}\end{array}$ & EST & VAC/EST & $5 / 9 / 2016$ & 2 \\
\hline 4 & Brasil & Sao Paulo & DEP & $\begin{array}{l}\mathrm{EST} / \mathrm{T} \\
\mathrm{RAB}\end{array}$ & VAC/VFA & $1 / 9 / 2016$ & 3 \\
\hline 5 & Brasil & NR & HOTEL & VAC & VAC & $7 / 9 / 2016$ & 2 \\
\hline
\end{tabular}




\begin{tabular}{|c|c|c|c|c|c|c|c|}
\hline 6 & Brasil & Fortaleza & HOTEL & VAC & - & 7/9/2016 & 1 \\
\hline 7 & Brasil & Salvador & HSTL & VAC & - & $8 / 10 / 2016$ & 1 \\
\hline 8 & Brasil & Paraiba/Rio & HSTL & $\mathrm{VAC}$ & VAC & $12 / 10 / 2016$ & 2 \\
\hline 9 & Brasil & Sao Paulo & HSTL & VAC & $\begin{array}{l}\text { VFA/VAC/ } \\
\text { TRA }\end{array}$ & $15 / 10 / 2016$ & 5 \\
\hline 10 & Brasil & $\begin{array}{l}\text { Rio de } \\
\text { Janeiro }\end{array}$ & HSTL & VAC & - & $15 / 10 / 2016$ & 1 \\
\hline 11 & Brasil & Curitiba & HSTL & VAC & - & $15 / 10 / 2016$ & 1 \\
\hline 12 & Brasil & Joa Pessoa & HSTL & VAC & - & $15 / 10 / 2016$ & 1 \\
\hline 13 & Brasil & $\begin{array}{l}\text { Sao Paulo / } \\
\text { Rio }\end{array}$ & HOTEL & VAC & - & $19 / 10 / 2016$ & 1 \\
\hline 14 & Brasil & Sao Paulo & HOTEL & VAC & - & $19 / 10 / 2016$ & 1 \\
\hline 15 & Brasil & Salvador & HOTEL & VAC & - & $12 / 11 / 2016$ & 1 \\
\hline 16 & Brasil & $\begin{array}{l}\text { Rio de } \\
\text { Janeiro }\end{array}$ & HOTEL & VAC & - & $12 / 11 / 2016$ & 1 \\
\hline 17 & Brasil & Sao Paulo & HOTEL & VAC & - & $14 / 11 / 2016$ & 1 \\
\hline 18 & Brasil & Recife & HOTEL & VAC & TRAB & $14 / 11 / 2016$ & $1 \mathrm{y} 4$ \\
\hline 19 & Brasil & $\begin{array}{c}\text { Belo } \\
\text { Horizonte }\end{array}$ & $\begin{array}{l}\mathrm{resid} / \mathrm{hstl} \\
\text { /HTL }\end{array}$ & VAC & $\begin{array}{l}\text { VAC/VAC } \\
\text { INT }\end{array}$ & $9 / 12 / 2016$ & 6 \\
\hline 20 & Chile & $\begin{array}{l}\text { Santiago de } \\
\text { Chile }\end{array}$ & $\begin{array}{l}\text { HOTEL/ } \\
\text { HOSTEL }\end{array}$ & VAC & vac & 4/9/2016 & 2 \\
\hline 21 & Chile & $\begin{array}{l}\text { Santiago de } \\
\text { Chile }\end{array}$ & HSTL & $\begin{array}{c}\mathrm{VAC} / \mathrm{E} \\
\mathrm{SP}\end{array}$ & VAC & $2 / 10 / 2016$ & 3 \\
\hline 22 & Chile & $\begin{array}{l}\text { Santiago de } \\
\text { Chile }\end{array}$ & $\begin{array}{l}\text { HTL } \\
\text { BTQ }\end{array}$ & $\begin{array}{l}\mathrm{VAC} / \mathrm{P} \\
\mathrm{ROF}\end{array}$ & VAC & $3 / 12 / 2016$ & 12 \\
\hline 23 & Paraguay & Asunción & $\begin{array}{c}\mathrm{DEP} / \mathrm{HT} \\
\mathrm{L}\end{array}$ & EST & VAC & $22 / 11 / 2016$ & 3 \\
\hline 24 & Paraguay & Asunción & $\begin{array}{c}\text { HTL/HS } \\
\text { TL/DEP/ } \\
\text { VFA }\end{array}$ & EST & $\begin{array}{c}\text { VAT/TRAB/ } \\
\text { CONG }\end{array}$ & $23 / 11 / 2016$ & 15 \\
\hline
\end{tabular}




\begin{tabular}{|c|c|c|c|c|c|c|c|}
\hline 25 & Uruguay & Montevideo & $\begin{array}{l}\text { HSTL/V } \\
\text { FA/RES }\end{array}$ & VAC & $\begin{array}{c}\text { EST/VAC } \\
\text { /VFA }\end{array}$ & $4 / 3 / 2016$ & 11 \\
\hline 26 & Uruguay & Montevideo & $\begin{array}{c}\mathrm{HTL} / \mathrm{VF} \\
\mathrm{A}\end{array}$ & VAC & $\begin{array}{c}\text { VAC/VFA/ } \\
\text { TRAB }\end{array}$ & $4 / 3 / 2016$ & 20 \\
\hline 27 & Uruguay & Montevideo & VFA & VAC & $\mathrm{VAC} / \mathrm{EV}$ & $6 / 3 / 2016$ & 4 \\
\hline 28 & Uruguay & Montevideo & $\begin{array}{c}\text { HTL/VR } \\
\text { F }\end{array}$ & VAC & $\mathrm{vac} / \mathrm{VFA}$ & $6 / 3 / 2016$ & 15 \\
\hline 29 & Uruguay & Montevideo & $\begin{array}{c}\text { HSTL/V } \\
\text { RF/htl }\end{array}$ & VAC & VFA/VAC & $6 / 3 / 2016$ & 8 \\
\hline 30 & Uruguay & Montevideo & $\begin{array}{c}\text { couch / } \\
\text { VFA/ } \\
\text { Hstl } \\
\end{array}$ & $\begin{array}{c}\mathrm{VAC} / \mathrm{E} \\
\mathrm{V}\end{array}$ & múltiples & $5 / 3 / 2016$ & 5 \\
\hline 31 & Uruguay & Montevideo & $\begin{array}{l}\text { couch / } \\
\text { hstl / } \\
\text { HTL }\end{array}$ & $\begin{array}{c}\mathrm{VAC} / \mathrm{E} \\
\mathrm{V}\end{array}$ & múltiples & $6 / 3 / 2016$ & 10 \\
\hline
\end{tabular}

Fuente: elaboración propia basada en la sistematización del trabajo de campo.

\section{Nociones teóricas sobre el Mercosur y su relación con el turismo y las movilidades}

El Mercosur es un bloque de integración regional, centrado en el intergubernamentalismo, que surgió en 1991 a través de la firma del Tratado de Asunción. Constituye un tipo de regionalismo abierto basado en una unión aduanera, cuyo pacto implica compromisos de cooperación económica, política y comercial (Malamud y Schmitter, 2006; Sanahuja, 2016). En las últimas dos décadas, en particular a partir de 2003, se le dio un mayor protagonismo a los aspectos sociales, ambientales, educacionales, culturales y productivos del bloque (Arrosa Soares, 2011; Botto, 2011). Esta ampliación de competencias y áreas de integración -basándose siempre en un diseño institucional intergubernamental e interpresidencialista- (Briceño Ruiz, 2011) incluyó al sector del turismo. En esa línea, desde la creación de las Reuniones Especializadas de turismo (RET) y las Reuniones de Ministros de Turismo (RMTUR), el turismo comenzó a ser considerado como un factor colaborativo y complementario a la integración regional, principalmente a través del dinamismo en las interacciones de actores que implica, como también en los diferentes mecanismos de cooperación y retroalimentación (Catalano, 2017; Comparato y Rucci, 2015).

En otro orden, cabe destacar la intrínseca relación entre el turismo y las movilidades para el caso del Mercosur, ya que gran parte de los avances que se han logrado en materia de turismo se corresponden con la facilitación en la circulación de ciudadanos de los Estados parte del bloque (Novick, 2010). Más allá de pensar el turismo desde un enfoque institucionalista, en lo que concierne a este trabajo se resalta la idea de integración regional que sobrepasa las relaciones entre Estados y que atiende a las relaciones entre las sociedades que los componen, tales como la hermandad, la unión, y 
una identificación mutua a partir de discursos y dispositivos culturales (De Sierra, 2001; Grimson, 2001).

\section{Lo regional desde los sujetos: el Mercosur desde los turistas}

A continuación, se esboza el análisis de los relatos de los turistas entrevistados, el cual comprende una categorización de representaciones según la recurrencia y/u omisión de ciertas variables mencionadas en el transcurso del trabajo de campo. Por un lado, predominan dos acepciones - que a simple vista podrían clasificarse como positivassobre las movilidades y la circulación de la población al interior de un bloque; por otro lado, una perspectiva crítica o sesgada sobre el Mercosur, con una asociación a lo comercial entre países, no equitativa y excluyente de participación ciudadana alguna.

\section{Movilidades y circulación intrarregional}

Se observa una asociación entre el Mercosur para los turistas y la libre circulación de personas entre los países que lo integran. Los sujetos entrevistados están interpelados por esta variable, dado que para concretar su viaje tuvieron que traspasar la frontera y en esta instancia de registro, como son los controles migratorios, deben presentar sus documentos que incorporan desde hace unos años la palabra "Mercosur". De hecho, muchos de los turistas, al preguntarles por el Mercosur, mencionan las palabras: "documento", "DNI", "viajar" y hacen referencia a que "esa palabra" se encuentra en el documento y a que por ello pueden ingresar sin pasaporte a un país extranjero como lo hicieron al llegar a Argentina.

En el colectivo de los relatos analizados prima la referencia a las facilidades de acceso, al no requerimiento de visa y a la libre circulación de personas. De hecho, en una ocasión un turista aseguró que gracias a que viajó y que en su documento decía "Mercosur", ahora, a partir de la pregunta que se le realizó, entendió "más fácil" lo que era el Mercosur.

Los turistas ejercen un juicio de valoración aduciendo que es "bueno" o "favorable" viajar de esa manera "sin barreras". Incluso se ha manifestado la comparación con la movilidad hacia otros países de la región, pero que no están dentro del acuerdo de documentación para países asociados, y con lo cual necesitan de pasaporte para su ingreso.

En este sentido, se observa un acercamiento ivdesde la perspectiva indidual sobre un proceso regional, principalmente a través del viaje que se encuentran realizando. La representación que el turista tiene sobre el Mercosur está más asociada a una perspectiva que trasciende a los intereses individuales, con la excepción de la movilidad, para los que su nivel socioeconómico les ha permitido viajar por placer, o bien, por necesidad u obligaciones. En lo que a la circulación de personas y a la 
temática migratoria se refiere, los procesos de integración, y en particular en el Cono Sur, tienen una gran importancia, sobre todo en los últimos años, debido al gran avance en materia legislativa institucional, como también al reconocimiento de la movilidad humana, considerada como un derecho esencial (Novick, 2013).

El impulso del turismo intrarregional en el Mercosur viene acoplado al impulso de las movilidades en general en el bloque, al facilitar la circulación y el tránsito de personas. Ello también tuvo cierta impronta desde el ideal de profundizar la unión, dado que existe una larga tradición cultural y de intercambio de bienes y desplazamientos poblacionales en estos países que data desde hace más de un siglo (Novick, 2013).

Es así como se observa una relación entre el turismo y otro tipo de movilidades semejantes a las migraciones. El aspecto común en ambas prácticas radica en el desplazamiento desde un lugar de residencia habitual hacia otro, y las diferencias se basan principalmente en las motivaciones que conducen a esos desplazamientos y al consecuente tiempo de permanencia y condición que adquiere el sujeto móvil en el destino.

Las movilidades internacionales han ido incrementándose en los últimos años. A su vez, a ello se le añade el acompañamiento de la regulación y los regímenes de movilidad, que coordinan los flujos de personas que atraviesan las fronteras (Glick Schiller y Salazar, 2013). La aceleración de los flujos y el incremento de velocidades no solo se corresponde a las personas; los objetos culturales como las imágenes, idiomas, las modas, se mueven con rapidez cada vez mayor, cruzando límites nacionales y regionales (Appadurai, 2015). La globalización y la transnacionalización inducen, de alguna forma, las movilidades internacionales y en ocasiones se agiliza la circulación de bienes, culturas y objetos al interior de una región, tal como ocurre en la Unión Europea y en particular en la movilidad estudiantil intrarregional (Fombona Cadavieco, Pascual Sevillano e Iglesias Martínez, 2015). Es en este contexto de creciente conectividad en el que las fronteras se vuelven porosas y permeables ante las condiciones de la globalización, los avances tecnológicos y el juego del mercado bajo el sistema capitalista, y en diversas regiones del mundo acontecen replanteamientos sobre la forma en la que las sociedades, instituciones, actores se integran.

\section{Tan solo un acuerdo de países (no equitativo)}

Ciertas representaciones de los turistas sobre el Mercosur descansan en concepciones generalistas y abstractas, poco perceptibles desde su realidad cercana. Prima la asociación a un acuerdo de países, un bloque económico y comercial. No se infiere una conciencia presente y realista sobre lo que es el Mercosur, sino que se observa una referencia a lo regional y a la región Sur, o bien, Latinoamérica.

Entre los relatos analizados emerge la idea de "bloque comercial" entre países, algo que pareciera eximir a los sujetos de su conocimiento sobre ello, parecido a algo que no les compete o les excede, porque corresponde a una escala o un nivel en los que ellos no se 
consideran intervinientes a primera vista. El alcance de la información sobre el bloque es limitado y está asociado a una cuestión económica, aduanera y comercial. En este sentido, lo que significa el Mercosur para los turistas se asemeja a lo que representó el bloque en la etapa inicial, es decir, una mera unión aduanera; no se mencionan aspectos de integración asociados a las dimensiones culturales o sociales. Incluso, se encontraron posiciones de decepción o descreimiento sobre el funcionamiento del bloque. Algunos alegan que la integración no funciona debido a la falta de interés de Brasil en el Mercosur, posicionando a este país como en un escalafón diferente en relación al resto. También se hace mención a una relación de dependencia, principalmente entre Argentina y Brasil, lo que transforma la integración en un juego de conveniencias y complementariedades. A pesar de que se percibe un acuerdo con la posibilidad de la unión latinoamericana, se cree que hay una barrera importante, asociada a lo lingüístico y demográfico.

Es notorio la recurrente mención a los "grandes" y "ganadores" (haciendo alusión a Argentina y Brasil) y a los "pequeños" y los "perdedores" (por Uruguay y Paraguay), percibido en reticencias a la integración por parte de ciertos relatos de los turistas de Paraguay. Hay una muestra de descreimiento de las verdaderas potencialidades de una concepción de integración solidaria y autonomista, dado que emerge una diferenciación en cuanto a los beneficios que obtiene cada país por su participación en el bloque.

El rol de los países como actores en el escenario internacional también resuena en las voces de los sujetos, transformando y hasta simplificando las relaciones entre Estados. Tal es así que para el caso de los uruguayos, se observa una necesidad de "aferrarse a los más grandes" porque si no, no podrían alcanzar un mayor desarrollo. En este sentido, Uruguay se visualiza como el país más pequeño, pero con gran potencial, al que le conviene aliarse a sus amigos vecinos, en particular a Argentina y Brasil, como una estrategia pragmática y realista sobre las asimetrías estructurales que caracterizan a los miembros del bloque como unidades nacionales independientes. ${ }^{3}$

La característica de ineficacia sobre el bloque de integración se plasmó en varios de los relatos, adjudicando esas características a la no complementación productiva, a la incapacidad del autoabastecimiento, como también a la dependencia hacia el mercado extrarregional y, por sobre todo, a la endeble importancia que se le da al mercado interno.

En pocos casos se observaron acepciones reflexivas, que traen un sesgo de incompleto o ineficiente. Aparentemente, solo con la veta comercial no alcanza, sino que además se requiere que se ejerza la integración social y cultural, lo que determina también un juicio valorativo crítico por parte de los entrevistados.

\footnotetext{
${ }^{3}$ Aquí se consigna un fragmento de la entrevista a la que se hace alusión según este análisis: "realmente es objetivo que vos tenés que presentarte al mundo en el sentido de eso, ir como bloque económicocomercial e ir con gente pesada. O sea, sino solos no somos nada" (turista de Uruguay, entrevista realizada el 6 de marzo de 2016).
} 
Si bien la integración aparece desde lo nominal y discursivo, ello no repercute en un resultado fructífero en cuanto a aspectos culturales y sociales de la integración. Existe una incompatibilidad estructural en ciertos aspectos, principalmente desde el plano ideológico e histórico, que marcan, de alguna manera, las líneas que recorrieron los países y actuaron en el escenario internacional ${ }^{4}$.

Como para recapitular, puede ser que no disten mucho las percepciones de los turistas que las de los mismos ciudadanos del Mercosur sobre el mismo bloque, pero sí se soslaya desde este relevamiento una general concepción volátil sobre lo que significa el bloque de integración regional en el que ellos mismos están inmersos como habitantes de los países que lo componen. Se rescata que los viajeros, como ciudadanos del Mercosur, hicieron efectivo el derecho a la movilidad a través de sus viajes. Ese aspecto refleja la articulación de escalas, ya que por un lado se está haciendo referencia a una normativa regional, por otro, a la circulación de los sujetos entre las fronteras de los países del Mercosur.

\section{Familiaridad y extranjeridad como indicadores de integración}

En este apartado se desarrollan las concepciones de extranjeridad, otredad, familiaridad y afinidad que son percibidas por los turistas regionales en relación con los ciudadanos del Mercosur. Uno de los principales paradigmas ligados al análisis del turismo contemporáneo tiene que ver con la extranjeridad y la familiaridad (Dann, 1996), aspectos determinantes a la hora de elucidar la integración social a partir de las prácticas de los sujetos móviles.

Se parte de la noción de extranjero, desde el formato legal y burocrático instituido cuando atravesamos fronteras, y también desde la figura social, que incluye el espacio como contenedor de esta condición del individuo en relación con su entorno. Es a partir de la extranjeridad que se puede concebir la integración a través del turismo como una vía de unión; y a la sociedad, como la suma de acciones recíprocamente orientadas en constante flujo y movimiento (Simmel, 2012). El supuesto desencadenante de la integración a través de las movilidades turísticas radica en que las acciones pueden ser transitorias o duraderas, estables o efímeras, y el conjunto de todas ellas conforman una red de hilos invisibles que tejen el entramado societal regional (Glick Schiller y Salazar, 2013). Cuando en este trabajo se hace referencia a la integración, se presupone que existe una diferenciación entre partes (Smith, 1989) que en algunos abordajes se denominan anfitriones e invitados, y que involucra una distinción en la que coexiste una condición de forastero por parte del visitante, o de invitado, el que llega a un lugar y que se denomina aquí "turista".

4 En Paraguay el Mercosur, en estos últimos tiempos, se veía así como algo que no sirve... nos quieren cagar... No había así como esa mirada de integración regional entre la gente. Después de lo que paso con el golpe de Lugo y demás pero más allá de eso lo que sé es que tienen diferentes agendas, de trabajo de grupos y eso. (Turista de Paraguay, entrevista realizada el 23 de noviembre de 2016) 
La extranjeridad que se analiza en este artículo se sustenta en la constitución de sentido de la acción social, en la que se observa la experiencia entre el pasado y el presente (Schutz, 2003). ${ }^{5}$ Por ello, se estudian las relaciones subjetivas a partir de la interacción en el mundo cotidiano y las experimentaciones de extranjeridad en los individuos que se encuentran en un lugar distinto de su lugar habitual o su lugar de origen, y que interactúan con el medio y con la sociedad que alberga ese destino. Asimismo, esta condición trae implícita la noción del otro que aparece representada en estructuras de alteridad, tales como los regionalismos, o nacionalismos (Augé, 1996). La condición de extranjero en el turista viene dada por las acepciones que el residente tiene sobre el sujeto que considera diferente, perteneciente a otro lugar, y no al lugar donde él se encuentra, por lo que también podrían determinarse distintos tipos de extranjeridades en función de la cercanía no solo física, sino cultural, emocional y relacional que se observa desde el fenómeno del turismo.

En esa línea es posible comprender las características de alteridad en los turistas a partir de ciertas expresiones que manifiestan y que hacen referencia a aspectos en sus viajes que les han llamado la atención o que les han resultado chocante. Una de las preguntas formuladas a los turistas es qué es lo que más les ha llamado la atención y si encontraron alguna diferencia importante en cuanto a prácticas culturales, interrogante que dio como resultado respuestas de las más variadas. La percepción por la diferencia se manifestó, por un lado, en algunos casos solo desde el lugar, tales como los edificios altos, o las magnitudes de la ciudad, o bien, relativas al estilo arquitectónico europeo. En otros casos les llamó la atención el estilo de interlocución por parte de los porteños, o bien, la gran predisposición a entablar conversaciones. También se encontraron diferencias en los hábitos tradicionales de los ciudadanos porteños, tales como que la vida activa comienza mucho más tarde en relación con el lugar de donde provienen los turistas, $\mathrm{u}$ otros aspectos como la arquitectura, la presencia de perros en la calle y la cantidad de plazas y áreas arboladas. Otros elementos de diferenciación manifestados por los turistas son los siguientes y se sintetizan a continuación: la forma en que funciona el transporte; la no presencia de negros en la ciudad; ciertos hábitos alimenticios y de vestimenta; el trato en los espacios públicos y en los comercios; las dinámicas urbanas, tales como la cantidad de ofertas culturales; y el uso intensivo de la cultura por parte de los ciudadanos.

A continuación se esboza un resumen del análisis, elaborado sobre los datos recolectados en el trabajo de campo. Aquí se concibe la alteridad desde las prácticas y vivencias de los turistas en sus estadías en la ciudad de Buenos Aires, especialmente desde las narrativas que componen los relatos en distintos momentos de las entrevistas. Sobre todo en relación con las preguntas que indagan acerca de sus autopercepciones como extranjeros en el destino visitado. Para ello, en lo que sigue se desarrollan dimensiones que permiten comprender las percepciones sobre extranjeridad en los

\footnotetext{
${ }^{5}$ Schutz (2003) estudia la situación de un forastero al interpretar el esquema cultural de un grupo social al que se acerca e intenta orientarse.
} 
turistas del Mercosur que visitan la ciudad de Buenos Aires, ya sea en términos de tiempo incurrido en el viaje, la receptividad, el lenguaje y la forma de comunicación que experimentaron en sus estadías.

\section{Factores que influyen en la integración}

Durante el trabajo de campo se realizaron preguntas que ahondaban en el sentirse extranjero en el destino. De este modo, el análisis de la información permitió encontrar recurrencias sobre los factores que incidían en sentirse extranjero o no sentirse extranjero por parte de los turistas. Así se esbozan algunas dimensiones que reflejan el análisis sobre la extranjeridad por parte de los visitantes y que de alguna forma permite comprender las relaciones entre las escalas de integración

- Tiempo en el destino

Uno de los elementos determinantes en la condición de extranjería es el tiempo incurrido en el lugar de destino. Ese espacio temporal contiene experiencias pasadas en torno a los viajes y al conocer el lugar y la sociedad. Las acciones de los sujetos móviles en el destino se despliegan en un espacio y tiempo determinados. Este tiempo de permanencia es denominado estadía o estadía promedio por las estadísticas, al aglutinar a un conjunto de turistas de determinada nacionalidad, o bien, de determinada categoría, por ejemplo: turista de negocios.

El factor tiempo de permanencia tiene que ver no solo con las noches o cantidad de días del turista en el destino, sino también con las veces que ha visitado, en este caso, la ciudad de Buenos Aires. Ello se ve claramente en algunos turistas que manifiestan una diferencia entre los inicios de su estadía y los momentos posteriores. Se observa que la mayoría de los turistas hace referencia a que en el momento de la entrevista sí se sienten extranjeros, pero aclaran que si se quedaran un tiempo más ahí, ya dejarían de sentirse extranjeros. Esto representa una relación indirecta entre el tiempo de permanencia y el percibirse como extranjero. A medida que se incrementa el tiempo de permanencia, se reduce la percepción de extranjeridad por parte de los viajeros. Ahora bien, el tiempo tiene una influencia en los lazos y relaciones que se gestaren, por ello es que se lo explicita como otro determinante sobre la extranjeridad, en tanto que la receptividad tiene que ver con el grado de acogida de la sociedad anfitriona (Smith, 1989).

Asimismo, se observa incidencia en el tiempo incurrido en otros viajes, en otros lugares distintos al de su residencia habitual. Para decirlo en otras palabras, si el turista es un viajero experimentado o no. En este sentido, la extranjeridad depende también de cuán familiarizado esté el turista con la extranjeridad. Los turistas manifiestan que como "ya están acostumbrados a viajar, no se perciben como extranjeros", haciendo alusión a sentirse raros o formar parte de otro lugar. Como ya han experimentado viajar a un destino internacional en vastas ocasiones, habitar y movilizarse en él resulta algo no tan raro o inhabitual. Esa afirmación parecería significar una contradicción, pero hace 
referencia al grado de adaptabilidad a los cambios, o a lo distinto por parte de un individuo, aspecto que también se desarrolla progresivamente.

Estas explicaciones preliminares se asientan en las voces de los turistas entrevistados, cuyas estadías en el destino variaron entre tres días y 48 días de permanencia. De esta forma pudo observarse una varianza representativa de distintos tipos de turistas. Ello se corresponde, a su vez, con el tiempo requerido para cualquier tipo de transacción social, a partir del cual son posibles de acoger situaciones de interacción social entre turista y residente. A mayor tiempo disponible, más posibilidades de encuentros entre residentes y locales, y menor el distanciamiento social al final del viaje.

- Receptividad y hospitalidad

La receptividad se refiere las formas en que los turistas son tratados en el lugar de acogida, que para el caso estudiado se manifiesta positivamente. Esta receptividad o trato alude al contacto que tuvieron con personas residentes en Buenos Aires, ya sean recepcionistas de hoteles/hostales, guías, vendedores de locales, o bien, residentes con los que interactúan intencionalmente, ya sea por mera casualidad, por encontrarse en la calle o en razón de que alguien se les acerque a orientarlos.

Este factor determinante de extranjeridad tiene su correlato en las concepciones de hospitalidad en el turismo, traducidas en percepciones sobre el trato que los turistas reciben de las personas que habitan el destino visitado, ya que la hospitalidad pareciera reducir la ansiedad que despierta en los extranjeros el adentrarse en lo que se denomina "desconocido"(Korstanje, 2010).

Esta connotación sobre el trato que reciben los turistas, la utilizan incluso comparando el trato habitual que reciben en sus lugares de residencia. Hacen comparaciones con las formas de interacción social que sucede en sus lugares de origen, aludiendo a que son más agresivos "allá", tal como lo expresaron en diversas ocasiones algunos de los turistas consultados, quienes manifiestan que en Buenos Aires "la gente parece más adecuada culturalmente". Tal es así que un turista entrevistado afirmó que:

En Brasil, la gente corre para conseguir un lugar en el metro [...] en Buenos Aires eso no sucede, la gente es más amable, acá nos sentimos más cómodos, y más respetados y las personas nos tratan como se espera. (Entrevista a turista brasileño, 11 de noviembre de 2016).

Un emergente llamativo del análisis de los relatos es la diferencia entre las expectativas de los turistas antes de la llegada al destino, y la experiencia efectiva. Un segmento importante de la población entrevistada hizo referencia a que venían con un imaginario errático respecto a lo que se encontrarían al llegar. Muchos turistas alegaron que antes de venir, las personas con las que hablaron, ya sea pidiendo recomendaciones o sugerencias sobre el destino, habían emitido un juicio de valor negativo sobre la receptividad. Sin embargo, al llegar se encontraron con algo muy distante de ello. Según un informante: "Entonces están los estereotipos que dicen: -'Ahh los argentinos son muito bravos!'”. Esta declaración corresponde a la de un entrevistado sobre la idea que tienen los brasileros sobre los argentinos cuando llegan a Buenos Aires. 
En la línea de "no sentirse extranjeros" se remite al "sentirse cómodo", "como en su casa", y a que no se sienten en un lugar al que no pertenecen. A ello se le añade las diferenciaciones en el trato interpersonal, en la cotidianeidad, en los chistes, en las formas de vestirse, de caminar, en rasgos físicos, o bien, en la no fluidez en la interacción.

Un aspecto para resaltar es pensar en que la receptividad positiva tiene correlación con la concepción mercantilista del turismo, según la cual se enfatiza en la hospitalidad, cordialidad y amabilidad como utilitario para contentar a los turistas. ${ }^{6}$ Bajo esta idea sobre el turismo, los turistas son clientes, consumidores, en los comercios, en los locales, en los restaurantes. No obstante, se observa una predisposición positiva, perceptible por los turistas en la vía pública, al indagar sobre alguna orientación, respecto de la cual muchos de ellos afirmaron haber recibido una grata respuesta y una humana atención.

Se observa también una diferenciación en el trato al extranjero turista y al extranjero no turista, sobre todo en las formas de interacción cotidianas, en los espacios públicos y en las acciones típicas de los ciudadanos. Pareciera que hay una forma en el trato hacia el otro que, por ejemplo para el brasilero, el residente de la ciudad de Buenos Aires va al choque por sus imperativos en el habla, como en la forma de dirigirse a los individuos en general, y que desde el punto de vista del turista extranjero lo califican como "chocante". A pesar de las diferencias en los modos y en las formas de hablar, una vez aprehendida esa diferencia por parte de los visitantes, las situaciones de interacción no resultaban chocantes para ellos. Asimismo, los prestadores que están más en contacto con turistas, tienen esta aptitud de adaptarse al modo para resultar menos chocante a la cultura distinta, dado que en los turistas tradicionales ${ }^{7}$ no se observó este tipo de choque en la socialización.

Finalmente, existe una parte de los entrevistados que encuentra "chocante" la personalidad del argentino en relación con la receptividad. Esa distancia se relata en percibir a los argentinos como "mala onda" o "mal genio" por parte de los turistas. Por otra parte, de alguna forma justifican esta connotación al hacer referencia a la vida en la ciudad, a la saturación de trabajo, al nerviosismo urbano, etc. Sobre todo por parte de los turistas cuyos lugares de origen son pueblos o ciudades pequeñas.

- Comunicación e idioma

La comunicación en el turismo es clave no solamente desde la perspectiva sociolingüística (Dann, 1996) y del marketing, sobre todo en la transmisión efectiva de atributos que contiene determinado destino turístico, sino también desde el

\footnotetext{
${ }^{6}$ Según el enfoque económico sobre el turismo, el turista es fuente de ingresos económicos y el gasto turístico se vuelve el principal indicador de esta actividad (Hiernaux-Nicolas, 2002).

7 Con turistas tradicionales nos referimos a los que realizan excursiones en bus y se alojan en establecimientos hoteleros. La cita refiere a un turista cuya modalidad es VFA ( visita a un familiar o amigo)
} 
relacionamiento que establecen los turistas a través de sus estadías en esos destinos. Teniendo en cuenta que uno de los más complejos enfoques de análisis sobre el turismo se vincula a las concepciones de extranjeridad y familiaridad, el lenguaje del turismo permite comprender el rol de las palabras y adjetivos en reafirmar lo exótico y lo cotidiano y en resaltar el contraste entre ambos. Según Dann (1996), es a través de lo discursivo y el lenguaje que los turistas pueden construir imágenes y expectativas a través de la información que se les provee, ya sea desde la industria turística, como desde otros medios.

La comunicación y forma de sociabilidad que encarnan los turistas con los habitantes locales son un factor determinante para analizar la extranjería. La cuestión idiomática es sustancial a la hora de ahondar en las formas de interactuar entre los visitantes y los anfitriones, haciendo la distinción entre distintos niveles de integración social (Huete, 2009). Por lo anterior, se esgrime que uno de los indicadores clave para detectar la integración social es la capacidad de comunicación, en la que el aspecto lingüístico y el idiomático tienen una influencia taxativa. Así, se analiza la forma de comunicarse entre turistas y residentes, o entre turistas y nexos o guías, que habitan en la ciudad y el impacto que ello produce en la integración.

De los países de donde provienen los turistas que conforman el universo de análisis, solamente en Brasil se habla una lengua distinta al idioma local, lo que genera la primera categorización cuando se aborda la integración social en relación con la comunicación y las barreras lingüísticas. Pero el idioma y la lengua no solo se asocian a la forma de relacionamiento y al entablar comunicaciones y conversaciones fluidas o no, sino que también denota cierto estigma o marca de otredad simplemente al hablar, dado que se percibe por parte del interlocutor un rasgo que revela pertenencia a otro lugar. Ello se refleja en un entrevistado de Brasil, de Sao Paulo, quien conoció Buenos Aires como turista y que luego decidió quedarse a vivir. Este, a pesar de que vive hace 8 años en Buenos Aires, tiene un tono muy particular, pues prácticamente su tono de portugués no se le ha ido. Entonces, al indagar sobre su sentimiento de extranjería en la ciudad, su respuesta fue contundente, como se demuestra en la cita a continuación:

¿Desde la primera a la tercera vez te sentiste extranjero?

Hasta hoy me siento extranjero... siempre me sentí extranjero... sin excepción. [...] es imposible que una persona de acá no me identifique como un extranjero... es imposible. Bueno, si yo tengo la boca cerrada, no. (Entrevista a turista brasilero estudiante, 1 de septiembre de 2016).

La extranjeridad en este hombre, cuya condición inicial fue la de turista y de a poco fue transformándose en un habitante más de la ciudad, nunca disminuyó, tanto que hasta el momento de la entrevista seguía sintiéndose extranjero. Su portugués aún se percibe en el habla, entonces a menos que no hable, puede ser que no lo traten como extranjero alguien que no lo conoce. De este modo, la extranjeridad es una percepción propia, pero también, el trato de terceros hacia él ejerce influencia. 
Además del aspecto lingüístico e idiomático hay una diferencia cultural muy grande que interpela las interacciones, sobre todo cuando son con personas que no ha tenido trato previo. Los turistas provenientes de Uruguay, Paraguay y Chile no presentan distinción alguna en cuanto a la comunicación. Algunos turistas chilenos hicieron referencia a que distinguen su extranjeridad inmediatamente a diferencia del uruguayo. Nuevamente, en este aspecto el rol del mercado se hace notar, dado que los turistas que circulan por sitios muy asiduos de turistas, suelen encontrar prestadores que hablan portugués. En cambio aparece una traba mayor en los lugares en los que no son tan transitados por turistas y los residentes no hablan portugués, puesto que la comunicación no se mantiene clara.

\section{Hermandad e identidad colectiva}

Retomando el supuesto que asocia al turismo con las nociones de hermandad y unidad entre los pueblos, en este apartado se ahonda sobre la dialéctica entre el enfoque conceptual y el enfoque empírico. Para ello se analizan los ideales de integración identificados por los turistas regionales a través de sus relatos.

La hermandad y la unión se ven manifiestas en el sentimiento de pertenencia a un lugar, a un territorio más amplio que el del Estado-nación. Se corresponde a una identificación común y colectiva, que en algunos casos se determina por las idealizaciones históricas y nacionales, como también por las características comunes en relación con hábitos, costumbres y prácticas de la cotidianeidad (Benvenuto, 2017; Grimson, 2001). La idea de integración en los turistas presenta algunos aspectos en común respecto a las concepciones de unión e integración social que se dan en las migraciones, concibiendo esta última como una "interpenetración de los miembros y elementos culturales de dos poblaciones en una única y nueva estructura social y cultural" (Solé et al. cit. en Abde, 2012, p. 162).

Para poder elucidar características de unidad por parte de los turistas, se aluden al reconocimiento mutuo y a la interculturalidad. Esta última, como proceso inmerso en el campo de las movilidades y del turismo en particular, que incluye dimensiones cotidianas, de extrañamiento frente a la alteridad, desigualdades sociales, así como dimensiones políticas (Grimson, 2000).

Al indagar en el plano individual sobre el reconocimiento mutuo, se observa una asociación directa con los procesos históricos y trayectorias de los países en general. En esa línea, en relación con los turistas brasileros se advierte cierto desconocimiento mutuo estructural, a pesar de la cercanía geográfica, tal como se expresa en un fragmento de una entrevista a una turista: "Somos vecinos, tenemos una historia en común, pero nos conocemos muy poco" (Nexo de turistas de Brasil, entrevista a una turista brasilera, 9 de marzo de 2016).

Posteriormente a este fragmento, la entrevistada vuelve a reflexionar sobre la pregunta planteando que es posible que en el caso del Brasil la hermandad sea menor con el resto 
de los países, y puede que ello tenga que ver con una cuestión idiomática o lingüística. Tal aspecto no estaría alejado de los sucesos históricos de conformaciones de cada uno de los Estados nacionales, colonialismo o procesos emancipadores. En este sentido puede afirmarse, tal como menciona De Sierra (2001), que las desigualdades históricas actúan como condicionantes "estructurales" de largo plazo que restringen los márgenes de maniobra en los procesos de integración.

Existen trayectorias históricas compartidas con los vecinos de Brasil, pero también muchas diferencias que constituyeron sociedades culturales nacionales muy distantes entre sí. De alguna manera, lo vivido históricamente se traduce en las relaciones actuales y se plantea la premisa sobre la correspondencia entre las desigualdades de desarrollo históricas y las desigualdades estructurales sociales que dificultarían la integración actual. ${ }^{8}$

Así como las realidades nacionales no pueden ser estudiadas aisladamente del sistema regional (De Sierra, 2001, p. 93), las formas de integración regional, sus vicisitudes y transformaciones tampoco pueden estar desvinculadas de las sociedades nacionales, lo que remite a un ir y venir constante en los diferentes niveles de análisis sobre procesos sociales multiescala.

Una variante que se abre al profundizar en las formas de hermandad y unión entre los pueblos, tiene que ver con la identificación colectiva y con los rasgos culturales compartidos. En este sentido se observa una diferencia en relación a cómo los turistas regionales conciben a Argentina como "más europea", como "diferente a la fisonomía nacional del resto de los países de la región". "Una de las particularidades que los turistas destacan de Buenos Aires, no solo como atractivo que impulsa su movilidad, sino también como consecuencia del descubrimiento de la ciudad al transcurrir sus días en ella, es "lo diferente que es la ciudad de Buenos Aires en relación al resto de Latinoamérica", como también el carácter de europeo, por su fisonomía y las características de los individuos que la habitan. Se concibe a Argentina, pero más precisamente a Buenos Aires, como un oasis regional, donde se encuentran prácticas culturales y escenarios visuales que difieren a la regularidad del Cono Sur. También se hace alusión a la noción de enclave europeo (Grimson, 2000), donde convive la diferenciación y asimilación entre los extranjeros y los argentinos.

Cabe destacar que sobre la hermandad argentino-chileno, se evidencia cierta tensión en comparación al resto de las relaciones de la población de turistas analizados. Se observa un traslado de los conflictos que acontecen a un nivel Estado-nación hacia el nivel microsocial; lo global se traslada a lo micro, a las interacciones entre los ciudadanos de estas nacionalidades, que en su momento enfrentaron situaciones geopolíticas

\footnotetext{
${ }^{8}$ Serna en De Sierra (2001) aborda la reconstrucción histórica de lo social en la construcción de la "sociedad nacional" desde la perspectiva temporal.

${ }^{9}$ De hecho, esta caracterización que el extranjero tiene de Buenos Aires como ciudad europea es uno de los principales atractivos para ellos, dado que justamente es "lo distinto", lo exótico, muy diferente de lo que está habituado a observar y habitar en sus lugares de residencia habitual.
} 
complejas, tales como los conflictos del Canal de Beagle o el caso Malvinas. Las diferencias entre países en términos de tamaño y poder, y sus peculiares conformaciones étnicas y regionales, así como sus conflictos limítrofes y territoriales han marcado el escenario actual de integración en términos de percepciones subjetivas sobre la identidad regional (Grimson, 2001).

En otro orden, la hermandad se asocia a las conexiones sobre consumos comunes, o bien, en relación con hábitos similares entre ciudadanos binacionales. Tal es así que para el caso de los turistas uruguayos, se observa un grado de afinidad superior en relación al resto de los conciudadanos regionales. Ello tiene su sustento también en la afinidad histórica que caracteriza a las sociedades de ambas naciones y al grado de fraternidad intensa que reflejan procesos sociales que avalan el discurso de la "hermandad" (Merenson, 2014). Los argentinos y los uruguayos presentan rasgos de identificación mutua, rasgos comunes, y ello responde también a la historia de la convivencia regional que acontece en las relaciones que se ven permeadas por acontecimientos sociohistóricos. La hermandad rioplatense que agrupa a las sociedades argentino-uruguayas se vinvula con los procesos políticos de relaciones bilaterales.

La identificación mutua por el hecho de compartir rasgos culturales, también se manifiesta en la patrimonialización del tango como elemento cultural binacional, proceso mediante el cual se revaloriza el recurso cultural y se lo consolida como parte de la cultura rioplatense (Gómez Schettini, Almirón y González Bracco, 2011).

Algunos uruguayos hacen mención a que sus consumos están supeditados por la oferta de productos y servicios argentinos, tales como partidos de futbol, programas de televisión, obras de teatro, bandas musicales, la forma de alimentación, sobre todo un elemento con gran identificación regional como el "mate", la vestimenta, etcétera. Desde las narrativas también se alude la hermandad en función de los rasgos de similitud actitudinal, como también de rasgos físicos y de desenvolvimiento en los espacios públicos. Los uruguayos en el exterior son considerados como argentinos, cuestión que fue mencionada en varias ocasiones por los entrevistados. De hecho, ante la pregunta: ¿qué es lo que más les llama la atención sobre Buenos Aires o sobre Argentina y los argentinos?, no aparecen rasgos de comportamientos sociales divergentes entre ambas sociedades, sino que lo que se destaca en este sentido es la dimensión espacial y territorial, las características de megalópolis. Es decir, lo que representa grados de cercanía entre ambas sociedades, dado que la novedad no está en el factor social, sino más bien en el territorial y en el social vinculado al fenómeno de la gran urbe.

Los turistas brasileros, por su parte, comentan la similitud que tienen con los argentinos respecto a la pasión por el futbol y a que ambos son receptivos, alegres y divertidos, sobre todo para con los turistas. También destacaron los hábitos recreacionales comunes, como el hecho de salir a tomar algo y la forma espontánea de desenvolverse en ámbitos de interlocución. Por otro lado, encuentran aspectos más disímiles en cuanto a hábitos alimentarios, vestimenta, o bien, hábitos recreacionales. 


\section{Conclusiones}

A modo de concluir reflexivamente en torno a lo analizado hasta aquí, y retomando el supuesto de situar al turismo como un vector de integración regional que condujo al objetivo de comprender las relaciones entre la integración a través de la intersecala, puede afirmarse que existe una distancia entre las concepciones de la integración regional que emanan desde el Mercosur por un lado; y en términos de la percepción de los ciudadanos, por el otro. Las acepciones empíricas perceptibles desde la escala individual, por parte de los turistas, se asocian con las movilidades y la circulación de los individuos al interior del bloque, aspectos estos que descansan en la legalidad regional del tránsito de fronteras internacionales y que también se reflejan en las movilidades en general.

La integración percibida por los turistas presenta variaciones según nacionalidades, tiempos de permanencia, lingüística, comunicación, idioma, viajes pasados, predisposición a interactuar con residentes, entre otros. Los factores determinantes de extranjeridad asociados a los sujetos móviles provienen de aspectos estructurales y subjetivos, tales como la historia común, hábitos compartidos, o bien, el tiempo de permanencia en el lugar o la intención de interactuar con el otro o no.

Ante un contexto en el que los regionalismos, adaptados a la intensificación de la globalización, son cada vez más cambiantes y heterodoxos, nuevas políticas y nuevos actores no estatales emergen como objetos de estudio para dimensionar y analizar la integración regional. Ello conlleva hacia un pluralismo epistemológico en el que se construyen nuevos enfoques de análisis que intercalan escalas y actores. Por un lado, escalas, porque abordamos el turismo como un fenómeno global en el que flujos turísticos circulan y se movilizan, en paralelo de la práctica turística que actúa como lente que permite evidenciar integración. Por otro lado, actores, porque nos alejamos del intergubernalismo clásico para analizar la integración y nos basamos en actores subnacionales, como es el caso de la ciudad de Buenos Aires; e incluso actores/sujetos sociales, como los turistas.

De lo recopilado hasta aquí aparecen concepciones de hermanamiento y unión desde lo microsocial y desde las representaciones que los sujetos tienen sobre una unión que excede lo nacional, aunque estos atributos no se asocian directamente con las nociones del Mercosur por parte de los turistas.

A su vez, pareciera forzado concebir la identidad regional sobre la base de la historia común de los pueblos que habitan la región, ya que ello implicaría incluir las disputas bélicas en torno al territorio, como también los conflictos con los pueblos originarios que datan de tiempos previos a la constitución misma del bloque de integración. A pesar de ello, las movilidades, como proceso dinámico, engendran integración desde múltiples escalas, sujetos, turistas y también desde la escala región, interestatal, haciendo las fronteras menos rígidas en los últimos años, al menos en el caso del Mercosur. La movilidad transporta sujetos, cultura y prácticas asociadas, y por la misma esencia del 
turismo ello implica circulación e intercambio de ideas, historias, encuentros e interacción entre sociedades.

\section{Referencias bibliográficas}

Abde, K. B. (2012). El proceso de integración social de los refugiados reasentados en la región de Valparaíso, Chile. Si Somos Americanos, Revista de Estudios Transfronterizos, 12(1), 155-180.

Amilhat Szary, A. L. (2009). El turismo transfronterizo en Los Andes centrales: prolegómenos sobre una geopolítica del turismo. Si Somos Americanos, Revista de Estudios Transfronterizos, 9(2), 63-100.

Appadurai, A. (2015). El futuro como hecho cultural: Ensayos sobre la condición global. Ciudad Autónoma de Buenos Aires: Fondo de Cultura Económica.

Arrosa Soares, M. S. (2011). Balance y perspectivas del Mercosur cultural: 20 años de existencia. En J. Briceño Ruiz (ed.), El Mercosur y las complejidades de la integración regional (pp. 301-317). Buenos Aires: Teseo.

Augé, M. (1996). El sentido de los otros. Actualidad de la antropología (1 ${ }^{\mathrm{a}}$ ed.). Barcelona, Buenos Aires y México: Paidós.

Benvenuto, J. (2017). Hermandad y resentimiento en la producción del discurso de integración en la frontera de Brasil, Argentina y Paraguay. En W. Soto Acosta (ed.), Repensar las fronteras, la integración regional y el territorio (pp. 71-78). Ciudad de Buenos Aires: CLACSO.

Bertoncello, R. (2002). Turismo y territorio. Otras prácticas otras miradas. Aportes y Transferencias, 6(2), 29-50.

Botto, M. (2011). Qué nos enseñan los 20 años del Mercosur. Nueva Sociedad, (232), marzo-abril de 2011, 17-25.

Botto, M. (2015). La transnacionalización de la educación superior : qué papel juegan los nuevos regionalismos en la difusión de estas ideas. El caso del Mercosur (1992-2012 ) en perspectica comparada. Revista Iberoamericana de Educación Superior, 6(16), 90-109.

Briceño Ruiz, J. (2011). El Mercosur y las complejidades de la integración regional. Buenos Aires: Teseo.

Catalano, B. (2017). Turismo e integración regional: el caso del Mercosur. Novas Fronteiras de Estudos em Turismo: Dialogando com as Relações Internacionais, São Paulo: InMod, 107-149.

Comparato, G. y Rucci, A. C. (2015, Septiembre). Reflexiones de política turística en el Mercosur: un desafío para la diversificación productiva regional. III Simposio 
Regionalismo Sudamericano, llevado a cabo en la Universidad Nacional de La Plata, en la Ciudad de La Plata.

Crang, M. (1998). Cultural Geography. London and New York: Routledge.

Dann, G. M. S. (1996). The Language of Tourism. A Sociolinguistic Perspective. Wallingford: CAB INTERNATIONAL.

De Sierra, G. (comp.) (2001). Los rostros del MERCOSUR: el difícil camino de lo comercial a lo societa. Buenos Aires: CLACSO.

Fombona Cadavieco, J., Pascual Sevillano, M. A. e Iglesias Martínez, M. J. (2015). Movilidad estudiantil Erasmus: De la fraternidad europea a la opción migratoria. Migraciones, (38), 163-183. DOI: https://doi.org/10.14422/mig.i38.y2015.007

Glick Schiller, N. y Salazar, N. B. (2013). Regimes of mobility across the globe. Journal of Ethnic and Migration Studies, 39(2), 183-200.

Gómez Schettini, M., Almirón, A. y González Bracco, M. (2011). La cultura como recurso turistico de las ciudades: El caso de la patrimonialización del tango en Buenos Aires, Argentina. Estudios y Perspectivas en Turismo, 20(5), 1027-1046.

Grimson, A. (2000). Interculturalidad y comunicación. Bogotá: Grupo Editorial Norma.

Grimson, A. (2001). Fronteras, migraciones y Mercosur. Apuntes de Investigación, 7, 68-101.

Guber, R. (2001). La etnografía, método, campo y reflexividad. Bogotá: Grupo Editorial Norma.

Hiernaux-Nicolas, D. (2002). Cómo definir el turismo. Un repaso disciplinario. Aportes y Transferencias, 6(2), 11-27.

Huete, R. (2009). Turistas que llegan para quedarse. Una explicación sociológica sobre la movilidad residencial. Alicante Universidad de Alicante.

Korstanje, M. E. (2010). Las formas elementales de la hospitalidad. Revista Brasileira de Pesquisa Em Turismo, 4(2), 86-111.

Malamud, A. y Schmitter, P. (2006). La experiencia de integración europea y el potencial de integración del Mercosur. Desarrollo Económico, 46(181), 3-31.

Merenson, S. (2014). Uruguayos en Buenos Aires: procesos sociales de marcación. Trabajos de legitimación y desigualdad entre el primer peronismo y las papeleras. DADOS. Revista de Ciências Sociais, 57(40), 93-122.

Modolo, V. (2012). Política migratoria regional. El caso de la residencia Mercosur (2002-2011). Revista Aportes para la Integración Latinoamericana, 18(26), 40-58.

Novick, S. (2010). Migraciones y Mercosur: una relación inconclusa. Buenos Aires: Catálogos SRL. 
Novick, S. (2013). Las migraciones en América Latina: Un factor clave para la integración regional. Avances en la legislación de Argentina, Bolivia y Uruguay. $\operatorname{RevIU}, 1(2), 1-29$.

Sanahuja, J. A. (2016). Regionalismo e integración en América Latina: de la fractura Atlántico-Pacífico a los retos de una globalización en crisis. Pensamiento Propio, 21(44), 29-76.

Sautu, R., Boniolo, P., Dalle, P. y Elbert, R. (2005). Manual de metodología. Buenos Aires: CLACSO.

Schutz, A. (2003). Estudios sobre teoría social (1 ${ }^{\mathrm{a}}$ ed.). Buenos Aires: Amorrortu.

Simmel, G. (2012). El extranjero. Sociología del extraño. Madrid: Sequitur.

Smith, V. (1989). Anfitriones e invitados. Antropología del turismo. Madrid: Endymion.

Solanas, F. (2014). El Mercosur, la educación superior y la circulación de profesionales frente al desafío de la globalización. En Mercosur (ed.), La integración regional en tensión (pp. 49-75). Buenos Aires: La Colmena.

UNWTO y UNESCO (2015). Declaración de Siem Reap sobre turismo y cultura: Construyendo un nuevo modelo de cooperación. UNWTO Declarations, Vol 24, $\mathrm{N}^{\circ} 1$ DOI: 10.18111/unwtodeclarations.2015.24.01

Vellas, F. (2004). Economía y política del turismo internacional. Madrid: Editorial Síntesis. 